\title{
Spatial Features of the Rat Hippocampal Vascular System
}

\author{
Peter Coyle ${ }^{1}$ \\ Department of Anatomy, The University of Michigan Medical School, \\ Ann Arbor, Michigan 48109
}

Received September 12, 1977

\begin{abstract}
Earlier investigations in this laboratory demonstrated paired internal transverse arteries and veins associated with the rat cornu Ammonis (CA), mapped the vessels, and suggested segmental distribution and drainage patterns. Further studies of the smaller branches and capillaries were required to resolve the presence or absence of structurally segmented or isolated capillary beds common to vertebrate forms having paired intramedullary arteries and veins. Adult Wistar rats were injected with inks to demonstrate the arterial or venous tree or both. Each of the CA3 internal transverse arteries usually supplies numerous small-diameter branches to the adjacent blade of the fascia dentata. Often a major ramus supplies CA1 before the artery branches most profusely near the deepest point of the hippocampal fissure to supply the extrahilar CA3 and portions of the area dentata. Other vessels are located in the subiculum, adjacent regions of CA1, and the area dentata. Branches of the CA3 vessels more nearly parallel the lateral hippocampal axis than either of the other two. Numerous microvascular rami distribute obliquely across the longitudinal and transverse axes. As readily observed from thick, cleared India ink tissue sections, the strata molecularelacumosum and oriens are more vascular than the stratum radiatum where the long axis of capillaries tends to be oriented parallel to the apical dendrites. Clearly a subzone of CA1 stratum pyramidale, but not CA3, is the least vascular $\mathrm{CA}$ region. The outer portion of stratum moleculare of the fascia dentata is more vascular than the inner third. Well-developed capillary plexuses exist adjacent to the vascular poor zone of stratum granulosum and CA1. Branches of the internal transverse veins, deep veins, and external veins drain CA3 fields. Evidence of nonexclusive pairing of the internal arteries and veins, multiple systems draining the CA3 field, and the presence of anastomosing capillary beds indicate that structurally isolated segmental microvascular organizations do not exist for C.A3 of the rat hippocampus.
\end{abstract}

1 The author expresses his appreciation to Betsey Stiepock for excellence in typing the manuscript. Project support was in part from a University of Michigan Biomedial Research Support Grant and The Michigan Heart Association.

Abbreviations: $\mathrm{CA}$-cornu Ammonis; FD-fascia dentata. 


\section{INTRODUCTION}

Relatively little is known of vascular transport systems in the hippocampal formation ${ }^{2}$ of common laboratory animals. Nilges (23) and Gillilan (16) observed a rake-like pattern of arteries stemming from the posterior cerebral artery, or one of its branches, to enter the hippocampal fissure in several species, but not the rat. Andersen et al. (2) briefly noted the pattern in the rabbit, suggested the existence of a similar pattern for veins, and considered the possibility of a segmental or lamellar neuronal organization of the hippocampus. The capillary length per unit volume of hippocampal tissue for various neuronal strata in rat (10) and rabbit (3) was estimated, but the quantitative data lack described cornu Ammonis (CA) regional values, and give no information about collateral vessels either external to or within the microvascular bed.

Recent vascular studies in our laboratory were directed toward mapping larger supply and drainage vessels of the rat septal region $(5,7)$ and hippocampal formation $(6,8,9)$. Major patterns of internal transverse arteries and veins were observed in the obliterated hippocampal fissure with branches in strata of CA3 and the fascia dentata (FD) being separate from systems of the $\mathrm{CAl}$ and subicular regions. Furthermore, smaller arteries in the $\mathrm{FD}, \mathrm{CA} 4$, and extraventricular $\mathrm{CA} 3$ region enter the formation via the external or alvear route. Accompanying external veins and the deep veins of the intraventricular CA3 field never enter the internal system. The large paired internal arteries and veins would suggest the possibility of a segmental vascular organization $(14,25,29)$ of C.A3 where the deep and external vessels could supplement the internal system.

A complete segmental vascular organization has morphologically isolated microvascular beds composed of nonanastomosing capillary fields. Such fields, common to the nervous system of some vertebrates $(11,13,19,26$, 27,29 ) and suggested by the presence of paired vessels in the rat CA archicortex, are an issue resolved by this investigation. Furthermore, the identification of structural features of the microvascular transport systems within spccific laminae was considercd necessary to provide a reference base

2 The term hippocampal formation was used to include the various fields of the hippocampus (or cornu Ammonis segments CA1-4 as designated by Lorente de Nó (20), the fascia dentata, and various subfields of the subiculum. Subregions of CA3 could not be precisely defined by nature of the preparations. The pyramidal and granule cell layers, fimbria, and alveus were clearly evident in the glycerin sections, and allow identification of strata superficial and deep to the cell layers. The two blades of the fascia dentata were named in accordance with their position relative to the hilum formed by CA1-3. The internal blade is adjacent to the hippocampal fissure. Such terminology is less confusing than the more routine dorsal-ventral blade classification when considering horizontal sections. 
for studies localizing microvascular-neuronal activity correlates in time and space.

\section{METHODS AND MATERIALS}

Fenale Wistar rats weighing 180 to $300 \mathrm{~g}$ were anesthetized with sodium pentobarbital ( $50 \mathrm{mg} / \mathrm{kg}$ body weight, intraperitoneally). After making a ventral thoracic opening, a No. 20 cannula was inserted through the left ventricle into the aorta and secured with a ligature. After clamping the aorta distal to the left common carotid artery and snipping the right atrium, $5 \mathrm{ml}$ undiluted Speedball fluorescent ink mixed with an equal amount of warm $2 \%$ agar made with physiologic saline was injected via a syringe under hand pressure in 10 rats. The ink particles and agar solution were of such size and consistency that the medium filled the arteries but not the capillary beds or veins. In 10 other rats the aortic cannula was utilized to flush the vascular tree with 30 to $50 \mathrm{ml}$ warm physiologic saline prior to cannula insertion and injection of the medium into the right jugular vein to demonstrate cerebral veins. To obtain vascular preparations where microvascular fields could be observed, $10 \mathrm{ml}$ undiluted Winsor Newton India ink was injected via the aortic route in more than 50 female animals. Injection of India ink followed by the fluorescent medium via the arterial or venous route provided another 20 double-injected brains where the arterial tree, venous bed, and microvascular field could be differentially distinguished.

All brains were fixed following immersion in 10\% neutral buffered formalin for at least 3 days. In many India ink specimens the hippocampus was dissected to allow sections to be cut normal to the longitudinal axis, ${ }^{3}$ which is not feasible using routine laboratory cuts of the whole brain. Sagittal, coronal, or horizontal sections less than $1 \mathrm{~mm}$ in thickness were cut from half or whole brains with a hand-held razor blade. The thick sections were cleared within $1 \mathrm{~h}$ and mounted on glass slides in glycerin. Cover slips were sealed with Permount. Observations were made with a standard light microscope, a dissecting microscope (for greater depth of field), and a microscope with xenon-generated ultraviolet light for fluorescence. The excitor filter was a Kodak No. 47, whereas Nos. 15 and 22 barrier filters were utilized.

3 The distribution of hippocampal vessels is most conveniently described with a reference coordinate system consisting of the three principal spatial axes. Parallel to the longest dimension of the hippocampus is the longitudinal hippocampal axis. Normal to it and in its plane of symmetry is the transverse axis pointing approximately to the hilum of the fascia dentata at one end, and to the entorhinal cortex at the other. The third principal axis of space, the lateral axis, is normal to the other two, is oriented in a direction parallel to the apical dendrites of straturn radiatum, and indicates the shortest dimension of the cornu Ammonis or fascia dentata. 


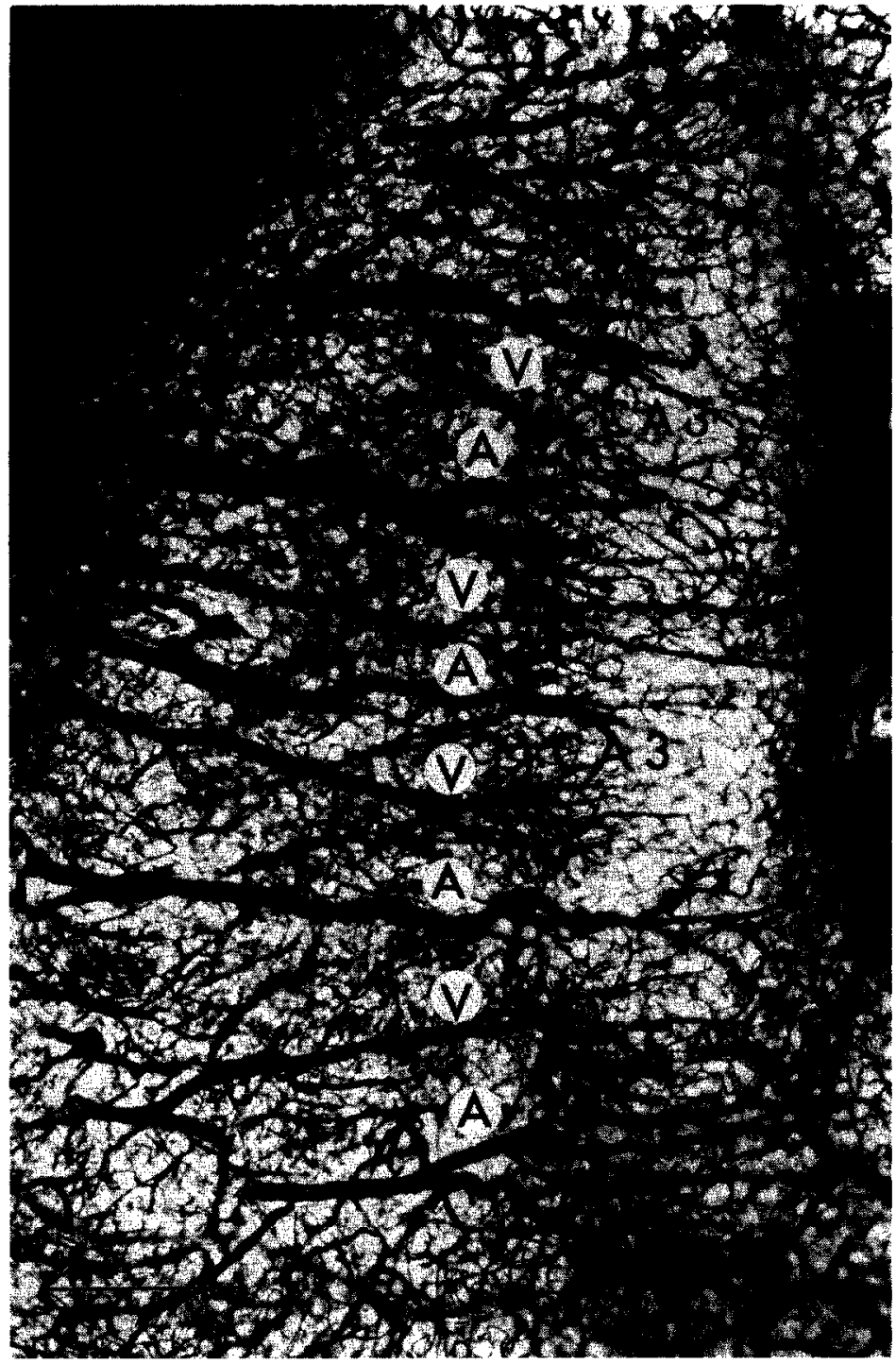

FIg. 1. Parasagittal section of the rat hippocampal formation. Note alternating sequence of the CA3 internal transverse arteries (A) and veins (V) and the tufted endings of the main trunk vessels. Arteries injected with fluorescent ink, veins with India ink. Fimbria at the right, subiculum at the left. Thick slice cleared in glycerin. Scale, $430 \mu \mathrm{m}$. Abbreviations used here and in the following figures: A-internal transverse hippocampal artery of cornu Ammonis segment 3; Ab. int. trans. hipp. a.aberrant internal transverse hippocampal artery; Brs. deep trans. hipp. vs.-branches of deep transverse hippocampal veins; Brs. ext. trans. hipp. ves.-branches of external transverse hippocampal vessels; Brs. ext. trans. hipp. vs.-branches of external transverse hippocampal veins; CA3-cornu Ammonis segment 3; Deep long. v.-deep longi- 


\section{RESULTS}

The longest and largest-diameter vessels in the hippocampal fissure are the CA3 internal transverse hippocampal arteries and veins. The spatial arrangement is such that the vessels are interlaced in alternating sequential patterns of arteries and veins along the entire extent of the longitudinal axis, as demonstrated in part by the sagittal cut in Fig. 1. In coursing from the longitudinal supply vessel located in the porta of the hippocampal fissure, the CA3 internal transverse arteries tend to converge in the CA3 region due to the longitudinal curvature of the hippocampal formation being less at the fimbrial edge compared to the arc length at the subiculum. Both arteries and veins branch most profusely near the depths of the obliterated fissure (Figs. 1, 2). In Fig. 1 where the arterial tree was injected with the fluorescent ink and the veins wcrc filled with India ink, the rami of $\mathrm{CA} 3$ arterial tufts can be observed to project into the microvascular field drained by two adjacent internal transverse veins. In addition, CA3 fields are drained by the deep and external transverse veins (Fig. 5). Exclusive pairing of one artery's microvascular field with but one CA3 vein clearly does not exist as a pattern in the rat hippocampal CA3 field.

In traversing the subiculum, the CA3 vessels neither discharge to nor receive from rami of that structure. Rather, vessels supplying and draining subicular fields (Fig. 2) are wedged in between the longer CA3 internal vessels (Fig. 1); they are not as long as, and do not have such large diameters as the CA3 arteries. They do not have the tufted terminations or supply numerous deep alvear veins as do the CA3 arteries.

The spatial organization of a CA3 arterial tuft with emlanating branches is best observed in Fig. 2. The pattern is such that all branches arise from a short segment of the parent vessel, some rami briefly course in the direction of the longitudinal axis, then all radiate across the transverse plane with the long-vessel dimension oriented nearly in the direction specified by the lateral hippocampal axis. ${ }^{3}$ The vessels are named accordingly. Without question, the lateral branches supply CA3 fields and sometimes, but not invariably, a branch extcnds into CA1. Ordinarily, a scp-

tudinal vein; Deep pl.--deep plexus; Deep trans. vs.-deep transverse veins; Deep trans. hipp. vs.-deep transverse hippocampal veins; Ext. pl--external plexus; Ext. trans. ves.-external transverse vessels; FD-fascia dentata; FI-fimbria; Fimb-fimbria; $H$. fascia dent.-hilum fascia dentata; Int. pl.-internal plexus; Int. trans. hipp. a.--internal transverse hippocampal artery; Int. trans. v.-internal transverse vein; Int. trans. ves.-internal transverse vessels; Lat. hipp. as.-lateral hippocampal arteries; Lat. hipp. vs.-lateral hippocampal veins; Sec. trans. hipp. vs.--secondary transverse hippocampal veins; St. gran.- stratum granulosum; St. lac.-mol.-stratum lacunosum-moleculare; St. mol.-stratum molcculare; St. or.-stratum oriens; St. pyr.-stratum pyramidale; St. rad.-stratum radiatum; V-internal transverse hippocampal vein of cornu Ammonis segment 3. 


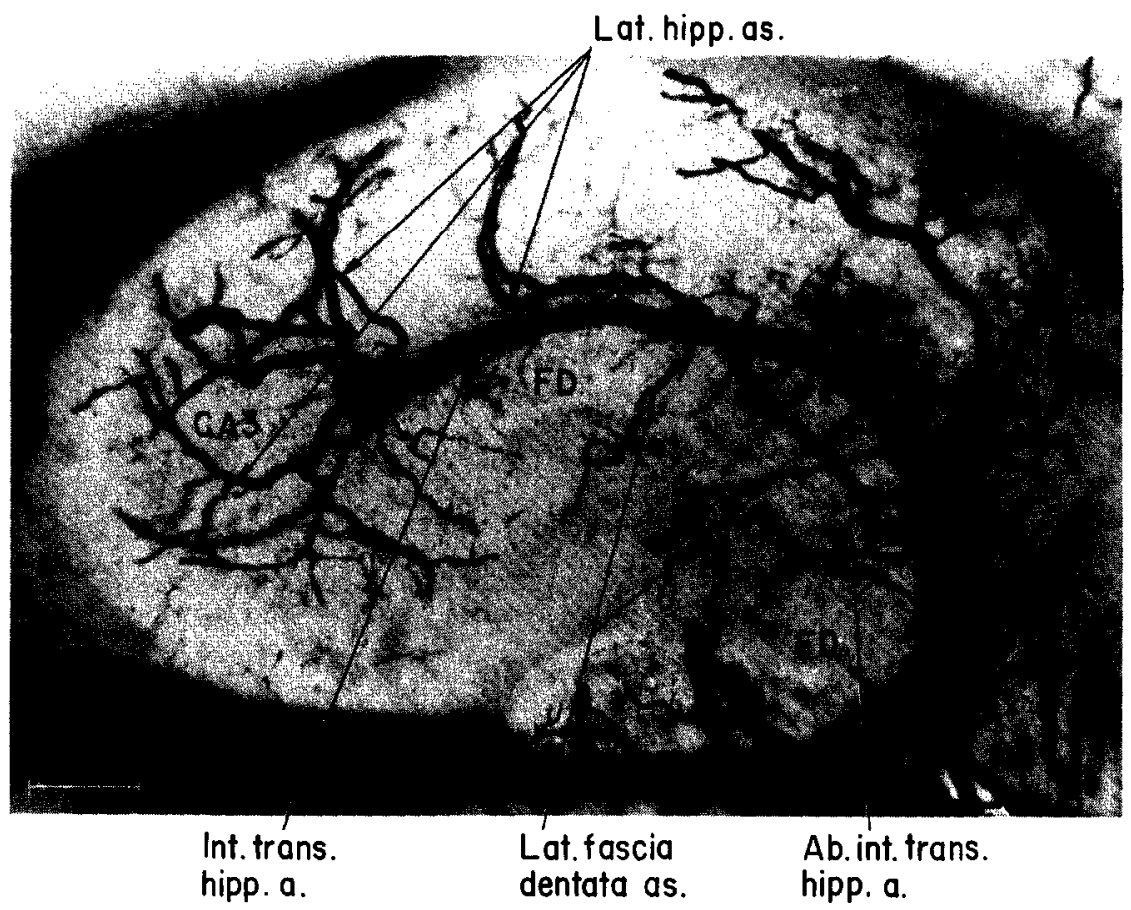

FIG. 2. Horizontal slice at the midpolar region of the rat hippocampal formation. Arteries injected with fluorescent ink. Arteries in subiculum are unlabeled. Thick section cleared in glycerin. Scale, $315 \mu \mathrm{m}$.

arate branch stems from the shank of the parent vessel, not the tufted ending, to supply portions of the CA1. The presence of this branch (Fig. 2) appears to depend on the extent of the field supplied by the tufted termination on one side and the field size of the subicular arteries on the other side.

Rami of the CA3 internal arteries are situated in the CA3 stratum moleculare-lacunosum, stratum radiatum, stratum lucidum, and all strata of the FD, and provide the microvascular field there. Stratum oriens and the microvascular plexuses of stratum pyramidale on the ventricular side of the fimbria are supplied in large part by smaller rami of these vessels. As can be readily observed in India ink sections (Fig. 4), branches of the external transverse vessels are in the extraventricular oriens and pyramidal layers and possibly extend into stratum lucidum.

Brains with India ink-injected vessels sectioned at several hundred micrometers in thickness and cleared in glycerin can be observed to have quite different microvascular patterns in various archicortical strata. Transluminated sections were observed to have an extremely complex microvascular field characterized by differences in capillary loop sizes, 
branching patterns, and vessel orientations dependent on the strata of localization. Boundaries of microvascular patterns are frequently as sharp as those separating the neuronal strata.

A number of microvascular field patterns are evident in Fig. 3. This India ink specimen was cut and aligned so that the long axis of the CA1 pyramidal cell somas and the apical dendrites in stratum radiatum were oriented at right angles to the optical axis of the microscope. One can observe a relatively poor vascularity within stratum pyramidale of CA1 (Fig. 3). However, fine capillary plexuses are at the soma boundaries. Both the superficial plexus on the apical side in stratum radiatum and the deep plexus on the basal side, probably among the scattered somas of

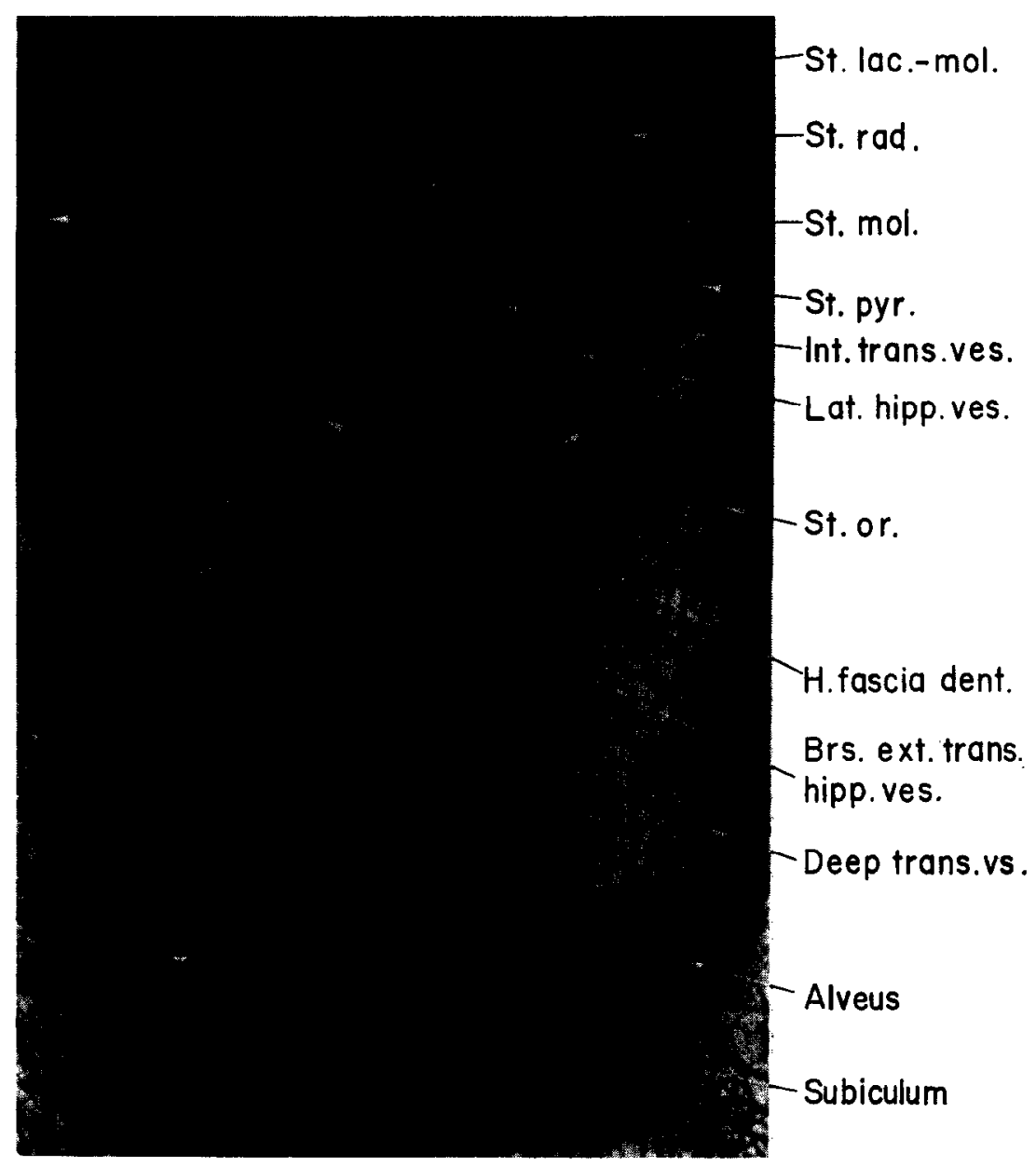

Fig. 3. Coronal section at the temporal end of the rat hippocampal formation. Vessels injected with India ink. Thick slice cleared in glycerin. Scale. $425 \mu \mathrm{m}$. 
stratum pyramidale, receive their blood supply from the lateral hippocampal arterioles and from capillaries in the vicinity. Other capillaries in the more richly endowed stratum radiatum tend to parallel the long dimension of the apical dendrites, but numerous obliquely oriented capillaries are present as interconnecting networks. In stratum oriens where double basal dendrites of adjacent pyramidal cells are not oriented in parallel (20) but rather intersect in arrangement, the capillary vessels branch more frequently in space, have greater length per unit volume of tissue, and have a more complicated spatial organization compared to stratum radiatum. Similarly, in stratum moleculare-lacunosum where the apical dendritic shafts branch most profusely, the parallel arrangement of adjacent fibers is lost and corresponding microvascular field patterns are comparable to those of stratum oriens.

Figure 3 illustrates a sharp vascular boundary between CA1 and the subiculum where the larger vessels of the fissure are more closely spaced and the microvascular patterns are less sharply defined according to strata, but where capillary vascularity appears greater near the fissure compared to deeper laminae. Other vascular differences can be noted between external and internal blades of the FD and interposed CA fields, but essential details are better illustrated in Fig. 4.

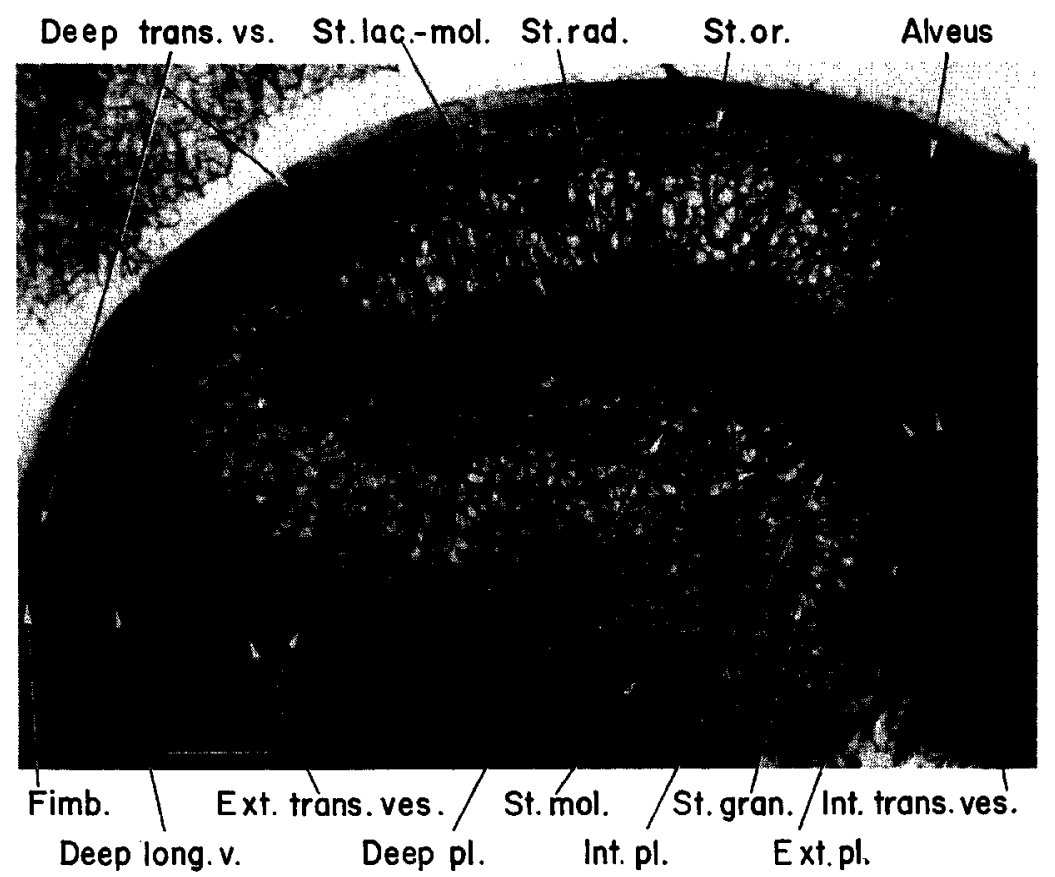

Fig. 4. Horizontal slice at the midpolar region of the rat hippocampal formation. Vessels injected with India ink. Specimen cleared in glycerin. Scale, $325 \mu \mathrm{m}$. 
In segments CA3 and 4 (Fig. 4), stratum pyramidale has neither the tight packing of cell somas, nor a relatively poor capillary zone within the lamina as in CA1. Stratum radiatum is the least vascular, whereas stratum moleculare-lacunosum or stratum oriens appears to be the most vascular. Quantitative estimates have differentiated the two $(3,10)$, but the CA regions of measurement are unknown. The vascular density of stratum oriens is greater near the pyramidal layer compared to regions near the fimbria or alveus (Fig. 4). No microvascular pattern differences were observed between stratum lucidum and stratum radiatum, even though the strata could be differentiated in thick sections.

Stratum moleculare of the FD is the most vascular layer (Fig. 4), but the capillary beds are not uniform in distribution across the lamina. Approximately the outer two-thirds where the external plexus is located is more vascular than the internal plexus of the inner third. Both plexuses are evident in the external and internal blades. Possibly differences exist in the vascularity along the longitudinal axis, but quantitative measurements were not made in this initial study. The relatively poorest microvascular zone of FD is where the granule cell somas are tightly packed. Here vascular communication is through the internal and deep plexuses abutting on apical and basal sides, respectively, of the multilayered granule cells. Supply to the plexuses is through lateral branches of the CA3 internal arteries for the internal blade; the external arteries supply the external blade.

The microvascular field of Ammon's horn and the fascia dentata is drained by at least four different sets of veins (Fig. 5). The precise extent of the microvascular field supplied by a given artery, and the region discharging into a given vein must vary with physiologic conditions in the field of anastomosing capillaries. In these preparations, the boundaries are indeterminate but venous rami are identifiable in various regions. The largest, longest, and most prominent veins are the CA3 internal transverse veins coursing in or parallel to the obliterated hippocampal fissure.

Branches of these vessels are in stratum moleculare-lacunosum and stratum radiatum of $\mathrm{CA} 3$ and all layers of the internal blade of the $\mathrm{FD}$, and a variable branch enters from CA1. The subiculum and portions of $\mathrm{CA} 1$ are drained by non-CA3 internal transverse vessels. The deep transverse veins course along the alvear surface or within its sulstance on the ventricular side of the fimbria, penetrate stratum oriens of $\mathrm{CA} 3$, and drain the microvascular field in the alveus, stratum oriens, and possibly the deep pyramidal plexus. On the extraventricular side of the fimbria, branches of the external transverse veins (Fig. 4) arise from the microvascular bed in the alveus, stratum oriens, stratum pyramidale, and possibly stratum lucidum to join collecting vessels receiving rami from CA fields within the hilum and from the external blade of the FD. 


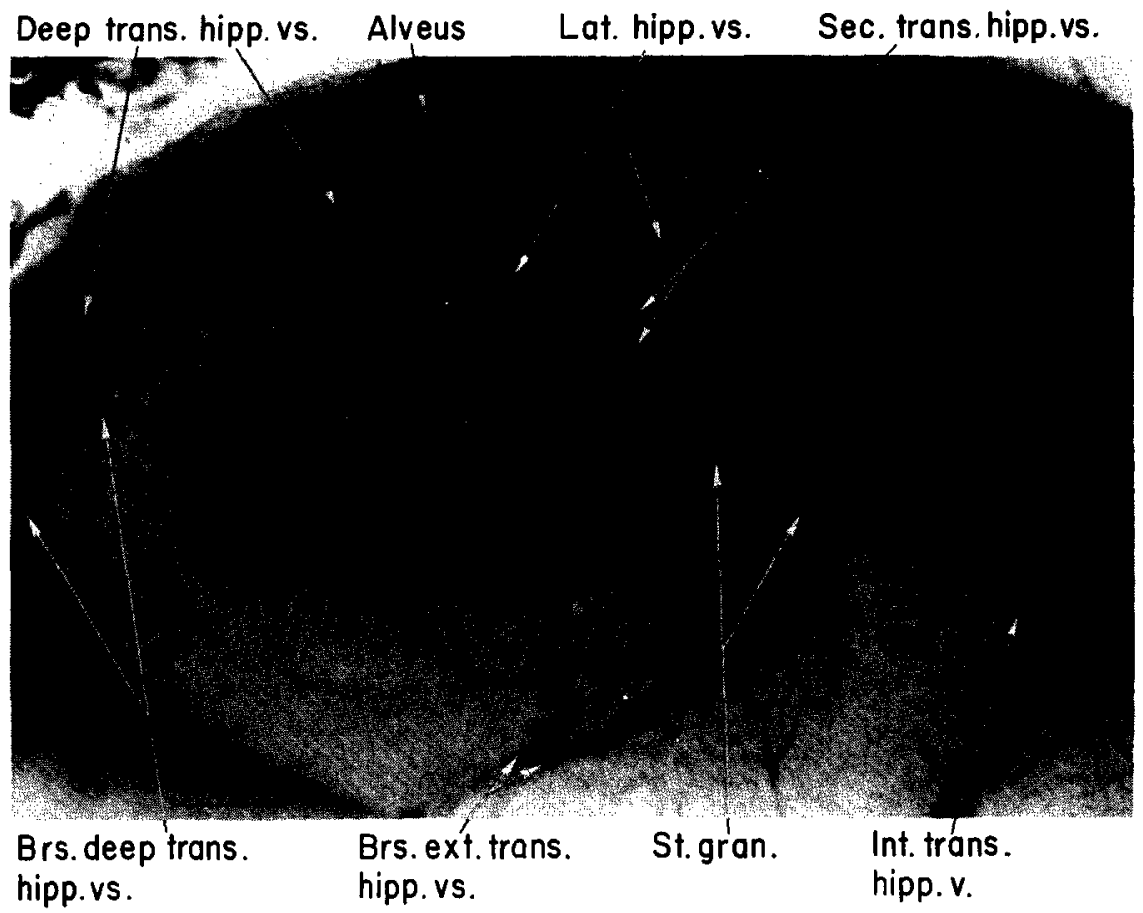

FIG. 5. Horizontal section through the temporal end of the rat hippocampal formation. Veins injected with fluorescent ink. Tissue cleared in glycerin. Scale, $250 \mu \mathrm{m}$.

\section{DISCUSSION}

Several fundamentally different types of gross vascular patterns and microvascular arrangements exist for vertebrate central nervous systems. In some aquatic forms, blood vessels never penetrate the medullary substance (14). Other species with arteries and veins located exclusively in the leptomeninges supply and drain unbranched intramedullary capillary loops (14). Animals with intramedullary arteries and veins have branched capillary loops. Although intramedullary arteries do not anastomose in many species (1), these vessels and veins of urodele amphibians and of some reptiles and marsupials are paired and course in close proximity to supply and drain nonamastomosing microvascular fields composed of branched capillaries $(11,13,26,27,29)$. In placental mammals, gross vessel branch patterns differ between the archi-, paleo-, and neocortices (18) and branched capillary loops supplied by different arteries are said to anastomose resulting in one continuous microvascular network or field (4).

The alternating sequence of internal arteries and veins along the long axis of the rat hippocampal archicortex suggested a pattern of paired vessels unlike those of the neocortex $(17,30)$. However, no evidence for 
structurally isolated CA3 microvascular fields was found, and exclusive CA3 vessel pairings are nonexistent for the rat CA3. Each CA3 internal artery supplies a field drained by two internal veins, rami of a deep alvear vein and possibly branches of an external vein. Obviously, the extent of the microvascular bed supplied by a given vessel is not without limit. Additional experimental studies are required to measure the boundaries of fields supplied by the CA3 vessels on the one side and the subicular vessels on the other.

The hippocampus and nucleus medialis septi of some vertebrates are telencephalic structures relatively richly endowed with blood vessels ( 7 , $12,24)$. Clearly, microvessel patterns are more complex in spatial organization in the synaptic zones (15). Quantitative vascular studies made more than 40 years ago demonstrated capillary density differences among the hippocampal strata $(3,10)$, but the findings differ from the present investigation in several respects. First, the earlier studies done with paraffin sections did not identify a vascular-poor zone in the CA1 stratum pyramiclale; possibly the reduced vascularity predisposes the cells to injury under certain conditions. Second, the measurements for stratum moleculare of the FD did not differentiate the vascular-poor inner region where septal, commissural, and association fibers course $(21,31,32)$ and the vascularrich outer zone receiving the entorhinal efferent fibers $(21,28)$; this could suggest different metabolic requirements for the fiber systems and receptor zones (15). Third, the earlier papers did not recognize the fine capillary plexuses adjacent to the pyramids and next to the granule cells where norepinephrine or serotonin fibers (22) possibly regulate the microvessels.

The fact is well known that the CA3 pyramidal cell apical dendrites are localized in stratum lucidum and outlying layers, whereas the basal dendrites are in stratum oriens. Microvascular findings of layer-specific vascular densities, the presence of specialized plexuses near the cell bodies, and particular capillary orientations correlate with synaptic density, the localization of nerve cell bodies, and the orientation of cell dendrites. More importantly, this structural organization is probably indicative of layerspecific vascular transport requirements and local regulatory mechanisms for specific subcellular regions of pyramidal neurons that remain to be functionally clarified.

\section{REFERENCES}

1. AвBIE, A. A. 1933-1934. The morphology of the fore-brain arteries, with especial reference to the evolution of the basal ganglia. $J$. Anat. 68:433-470.

2. Andersen, P., T. V. P. Bliss, ANd K. K. Skrede. 1971. Lamellar organization of hippocampal excitatory pathways. Exp. Brain Res. 13: 222-238. 
3. CoвB, S. 1921. The cerebral circulation. VIII. A quantitative study of the capillaries in the hippocampus. Arch. Surg. 18: 1200-1209.

4. CoвB, S. 1931. The cerebral circulation. XIII. The question of "end-arteries" of the brain and the mechanism of infarction. Arch. Neurol. Psychiat. $25: 273-280$.

5. Coyle, P. 1973. The arterial supply to the rat septum. Anat. Rec. $175: 502$.

6. Coyle, P. 1975. Arterial patterns of the rat rhinencephalon and related structures. Exp. Neurol. 49 : 671-690.

7. Coyle, P. 1976. Arterial and venous vessel patterns in rat septal structures. Pages 133-146 in J. F. DeFrance, Ed., The Septal Nuclei. Plenum Press, New York.

8. Coyle, P. 1976. Vascular patterns of the rat hippocampal formation. Exp. Neurol. 52: 447-458.

9. Coyle, P. 1977. Small vessel patterns of the rat hippocampal formation. Anat. Rec. 187: $558-559$.

10. CRaigie, E. H. 1930. The vascular supply of the archicortex of the rat. I. The albino rat (Mus norvegicus albinus). J. Comp. Neurol. 51: 1-11.

11. Cratgie, E. H. 1938. The blood vessels of the brain substance in some amphibians. Am. Phil. Soc. Proc. 78 : 615-649.

12. Craigre, E. H. 1939. Vascularity in the brains of tailed amphibians. I. Ambystoma tigrimum (green). Am. Phil. Soc. Proc. $81: 21-27$.

13. Craigie, E. H. 1940. Vascularity in the brains of tailed amphibians. II. Necturus maculosus rafinesque. Am. Phil. Soc. Proc. 82: 395-410.

14. Craigie, E. H. 1954. Vascular patterns of the developing nervous system. Pages 28-49 in H. WaELSCH, Ed., Biochemistry of the Developing Nervous System. Academic Press, New York/London.

15. FRIEdE, R. L. 1966. Capillarization. Pages 1-15 in R. L. FRIEdE, Ed., Topographic Brain Chemistry. Academic Press, New York/London.

16. Gillilan, L. A. 1976. Extra- and intra-cranial blood supply to brains of dog and cat. Am. J. Anat. 146: 237-254.

17. Greene, E. C. 1935. Anatomy of the rat. Trans. Am. Phil. Soc. N.S. $27: 1-370$.

18. Lazorthes, G., Espagno, J., Lazorthes, Y., and J. O. Zadeh. 1968. The vascular architecture of the cortex and the cortical blood flow. Pages 27-32 in W. Luyendi K, Ed., Cerebral Circulation, Progress in Brain Research, Vol. 30. Elscvier, New York.

19. Lewis, O. J. 1957. The form and development of the blood vessels of the mammalian cerebral cortex. J. Anat. 91 : 40-46.

20. LoRente DE Nó, R. 1934. Studies on the structure of the cerebral cortex. II. Continuation of the study of the ammonic system. J. Psychol. Neurol. 46: 113-177.

21. Lynch, G., ANd C. W. Cotman. 1975. The hippocampus as a model for studying anatomical plasticity in the adult brain. Pages 123-154 in R. L. IsAACSON AND K. H. Pribram, Eds., The Hippocampus, Vol. I. Plenum Press, New York.

22. MoORE, R. Y. 1975. Monoamine neurons innervating the hippocampal formation and septum: Organization and response to injury. Pages $215-237$ in R. L. IsAacson and K. H. Pribram, Eds., The Hippocampus, Vol. I. Plenum Press, New York.

23. Nilges, R. G. 1944. The arteries of the mammalian cornu Ammonis. J. Comp. Neurol. $80: 177-190$.

24. Prolo, D. J., and D. L. Stilweld, Jr. 1962. Arterial supply of the diencephalon and some associated areas of the rabbit brain. J. Comp. Neurol. $119: 229-254$.

25. Scharrer, E. 1940. Arteries and veins in the mammalian brain. Anat. Rec. 78: 173-196. 
26. Scharrer, E. 1940. Vascularization and vulnerability of the cornu Ammonis in the opossum. Arch. Neurol. Psychiat. 44: 483-506.

27. Scharrer, E. 1944. The blood vessels of the nervous system. Q. Rev. Biol. 19: 308-318.

28. Steward, O. 1976. Topographic organization of the projections from the entorhinal area to the hippocampal formation of the rat. J. Comp. Neurol. $167: 285-314$.

29. Wislocki, G. B., and A. C. P. Camprell. 1937. The unusual manner of vascularization of the brain of the opossum (Didelphys virginiana). Anat. Rec. 67: $177-192$.

30. Zeman, W., and J. R. M. Innes, Eds. 1963. Pages 30-49 in Craigie's Neuroanatomy of the Rat. Acadimec Press, New York/London.

31. Zim MER, J. 1971. Ipsilateral afferents to the commissural zone of the fascia dentata, demonstrated in decommissural rats by silver impregnation. J. Comp. Neurol. 142: 393-416.

32. Zimmer, J. 1973. Extended commissural and ipsilateral projections in postnatally de-entorhinated hippocampus and fascia dentata demonstrated in rats by silver impregnation. Brain Res. 64 : 293-311. 